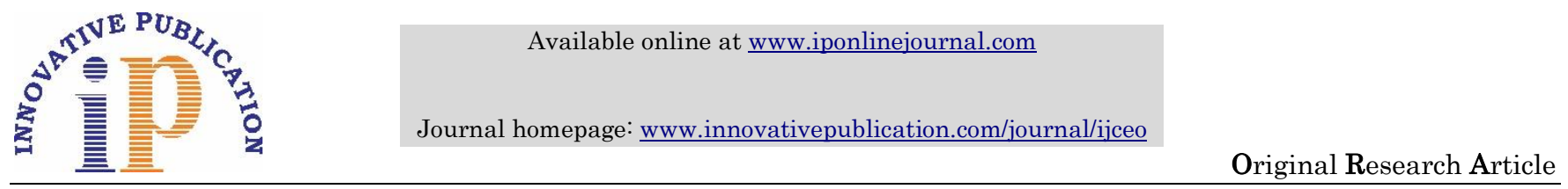

\title{
Prevalence of computer vision syndrome among computer users of Kolar district
}

\author{
Darshan. S.M ${ }^{1}$, Sangeetha. $\mathbf{T}^{2 *}$, Mohan Kumar $\mathbf{H}^{3}$ \\ ${ }^{1}$ Senior Resident, ${ }^{2}$ Associate Professor, ${ }^{3}$ Professor, Dept. of Ophthalmology, Sri Devaraj Urs Medical College, Kolar, Karnataka, India
}

\section{Article Info}

Received: $12^{\text {th }}$ March, 2019

Accepted: $11^{\text {th }}$ April, 2019

Published Online: $9^{\text {th }}$ September, 2019

Keywords: Blurred vision, Computer vision syndrome, Dry eye, Eye strain, Headache.

\begin{abstract}
Introduction: To evaluate the prevalence and the factors associated with Computer Vision Syndrome.

Materials and Methods: This cross-sectional, descriptive, questionnaire based, nonrandomized study included 320 professionals. After obtaining written consent subjects were asked to fill a set of questionnaire to get their personal information including demographic data (age, gender, occupation) and information regarding computer usage.

Results: A total of 320 participants aged between 16 to 55 years were surveyed. The prevalence of symptoms of CVS was found to be 70.3\%. 97 (33\%) individuals used computer around 4-6 hours per day. The most frequently observed symptom was headache seen in 176 individuals $(55.1 \%)$ followed by neck, shoulder, wrist or back pain in 155 (48.5\%), dryness of eyes in 128 (39.9\%) \& blurred vision in 118 (36.9\%) individuals. 42 participants (12.4\%) were aware of CVS. 261 participants $(81.6 \%)$ took preventing measures and the most common preventive measure was taking breaks in between work. Conclusion: Around $70.3 \%$ of surveyed participants experienced symptoms related to CVS. Out of 320 participants only 42 participants (12.4\%) were aware of CVS. Some of the strategies found beneficial in reducing the symptoms are keeping the computer screen away which reduces eye strain, taking regular small breaks, maintaining good sitting posture to avoid neck pain and back pain, correction of visual problems and optimum room lighting.
\end{abstract}

\section{Introduction}

Computer vision syndrome (CVS) is a group of symptoms experienced by most of the computer users. It is a repetitive strain disorder ${ }^{1}$ defined by the American Optometric Association as "The combination of eye and vision problems associated with the use of computers". ${ }^{2}$ The most common symptoms associated with CVS are eyestrain, irritation, blurred vision, dry eyes, diplopia, headaches, neck and shoulder pain after prolonged computer usage.,

These symptoms may be caused by longer duration of computer usage, improper sitting posture, poor lighting, glare and reflection on the computer screen, improper viewing distances, uncorrected vision problems or a combination of these factors. Longer periods of computer work were also associated with decreased blink rate which is a risk factor for dry eye and subsequent irritation of the eye.

Due to the increased workload, less break time and noncompliance in using personal protective accessories the burden of CVS has become one of the leading cause of occupational hazard. Constant gazing at the digital monitor causes decreased blink rate that cause increased exposure of cornea eventually resulting in severe dry eyes. ${ }^{1}$

It has also been observed that blink rate also decreases as font size and contrast are reduced, ${ }^{5}$ or the task demands increased conscious mental processing. ${ }^{6}$ In addition to this, voluntary eyelid squinting was observed to reduce the blink rate significantly. ${ }^{7}$

The severity of symptoms experienced by an individual often depends on the amount of time spent looking at the computer screen and number of breaks taken during their working hours and level of their visual status. Uncorrected refractive errors like hyperopia and astigmatism, inadequate convergence and accommodation can all contribute to the development of visual symptoms when using a computer.

\section{Materials and Methods}

This was a descriptive, cross sectional, non- randomized, questionnaire based study involving 320 individuals of both gender, who were asked to fill a set of questionnaire to get their personal information including demographic data (age, gender, occupation) and information regarding computer usage.

The study was approved by Institutional Ethics Committee of Sri Devaraj Urs Academy of Higher Education and Research and included individuals within age group of 20-50 years, spending 4 hours or more in front of a visual display terminal and not known to be suffering from

\footnotetext{
*Corresponding Author: Sangeetha. T, Associate Professor, Dept. of Ophthalmology, Sri Devaraj Urs Medical College, Kolar, Karnataka, India

Email: sangeetha31jayakumar@gmail.com

http://doi.org/10.18231/j.ijceo.2019.078
} 
any ocular disorder such as chronic ocular allergy, conjunctivitis, glaucoma, etc other than refractive errors. Individuals with anisometropia, amblyopia, tropia, myopic surgery, Keratoconus, allergic conjunctivitis, pterygium, uveitis, cataract surgery and glaucoma were excluded in this study.

With $69.3 \%$ prevalence, $95 \%$ confidence and absolute error of $5 \%$ the calculated sample size in this study was 320 individuals fulfilling the inclusion criteria. Data were collected by validated questionnaires focusing on the patient demographic parameters frequency of occurrence of the symptoms (number of episodes per week), intensity of 12 symptoms (burning, eye pain, headache, eye redness, photophobia, tearing, repeated blinking, heavy eyelids, itching, blurred vision at distance and near, and double vision) \& workers were then classified as asymptomatic, mild or intense symptomatology according to the score obtained on the questionnaire, yielding a CVS prevalence.

\section{Statistical Analysis}

Descriptive statistics was done like frequencies and proportions was computed and analyzed using SPSS 22 version software. Quantitative variables were represented as mean and standard deviation. Student t test was the test of significance for quantitative data and chi-square for qualitative data. All statistical analysis evaluated at $\mathrm{p}$ value $<0.05$ was considered as statistically significant.

\section{Results}

All the 320 individuals fulfilling the inclusion criteria responded to the questionnaire completely. The mean age of the participants was 23.43 years (20-50 years) among whom females $(55.9 \%)$ were more than males $(44.1 \%)$. [Table $1 \&$ 2]

The prevalence of computer vision syndrome was found to be $70.3 \%$. About 97 (33\%) individuals used computer around 4 - 6 hours per day. [Table 3]

The most disturbing symptom was eyestrain and fatigue in $198(61.8 \%)$, headache $176(55.1 \%)$, pain in neck, shoulder, wrist or back in $155(48.5 \%)$, dryness of eyes in $128(39.9 \%)$ \& blurred vision in 118 (36.9\%) individuals. [Fig. 1].

42 participants (12.4\%) were aware of CVS. 261 participants $(81.6 \%)$ took preventing measures and the most common preventive measure was taking breaks in between work.

Table 1: Age distribution

\begin{tabular}{|c|c|c|c|c|c|c|}
\hline Age & Frequency & Percent & Mean & SD & Min & Max \\
\hline < 20 years & 102 & 31.9 & \multirow{3}{*}{23.43} & \multirow{2}{*}{6.379} & \multirow{2}{*}{17} & \\
\cline { 1 - 3 } 21 to 30 years & 186 & 58.1 & & & \\
\cline { 1 - 3 } 31 to 40 years & 20 & 6.3 & & & \\
\hline 41 to 50 years & 9 & 2.8 & & & \\
\cline { 1 - 3 } > 50 years & 3 & 0.9 & & & \\
\hline
\end{tabular}

Table 2: Sex distribution

\begin{tabular}{|c|c|c|}
\hline Sex & Frequency & Percent \\
\hline Male & 141 & 44.1 \\
\hline Female & 179 & 55.9 \\
\hline Total & 320 & 100 \\
\hline
\end{tabular}

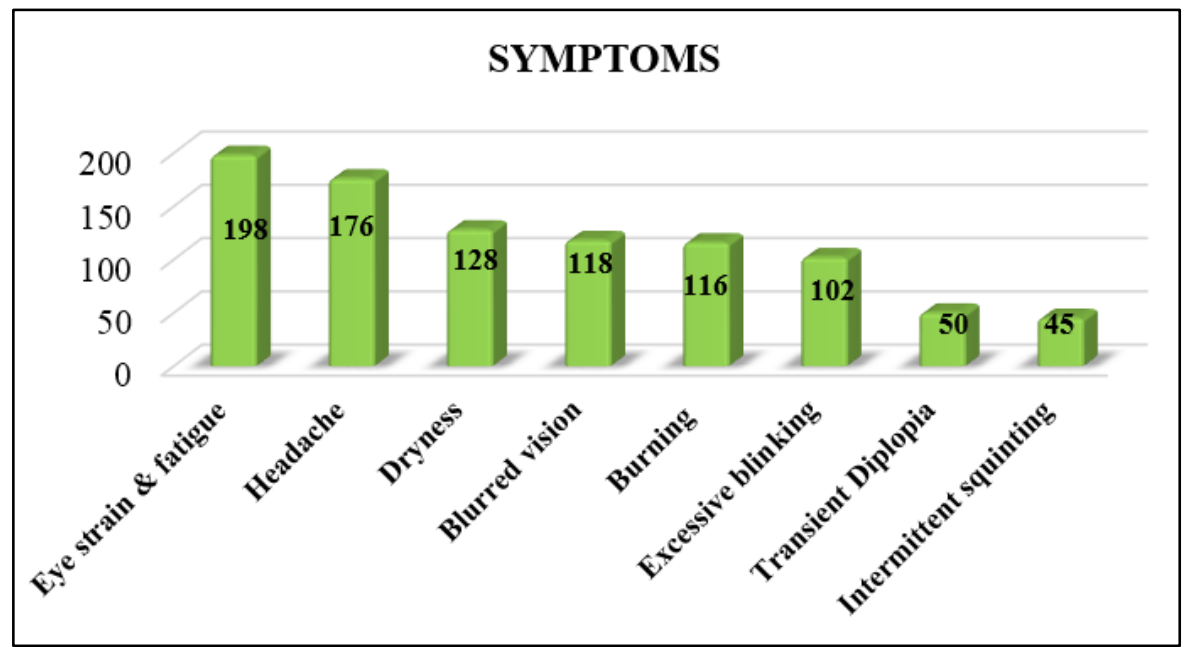

Fig. 1: Disturbing symptoms 
Table 3: Time spent on computer

\begin{tabular}{|c|l|c|c|}
\hline S. No & \multicolumn{1}{|c|}{ Factors } & Symptoms of CVS & Percentage \\
\hline 1 & Duration of computer use per day & & \\
& $\bullet<2 \mathrm{hrs}$ & 180 & 56.3 \\
& $\bullet 2-4 \mathrm{hrs}$ & 97 & 30.3 \\
& $\bullet \quad>4 \mathrm{hrs}$ & 43 & 13.4 \\
\hline 2 & Mobile Use per day & & \\
& $\bullet \quad<2 \mathrm{hrs}$ & 80 & 24.7 \\
& $\bullet \quad 2-4 \mathrm{hrs}$ & 95 & 29.7 \\
& $\bullet \quad>4 \mathrm{hrs}$ & 145 & 45.3 \\
\hline 3 & Taking breaks in-between work & & \\
& $\bullet \quad$ Every 20 min & 1 & 27.2 \\
& $\bullet$ Every 50 min & 142 & 0.3 \\
& $\bullet \quad$ Every 60 min & 23 & 44.4 \\
& $\bullet \quad$ Every 2 hour & 59 & 2.5 \\
& $\bullet$ More than every 2 hours & 7.2 \\
& $\bullet \quad$ No & & 18.4 \\
\hline
\end{tabular}

\section{Discussion}

In the study the mean age of the participants was 23.43 years (20-50 years) among whom females $(55.9 \%)$ were predominant than males $(44.1 \%)$.

In our study the prevalence of symptoms of CVS was observed to be $70.3 \%$ which was comparable to a study by Seshadhri et al. ${ }^{8}$ and lesser than other studies which showed $89 \%{ }^{9}$ and $80.3 \% .^{10}$

The most common symptoms in our study was eyestrain and fatigue $(61.8 \%)$, headache $(55.1 \%)$, pain in neck, shoulder, wrist or back (48.5\%), dryness of eyes $(39.9 \%) \&$ blurred vision $(36.9 \%)$ individuals. Blurred vision $(42.4 \%)$, headache $(23.0 \%)$ and redness $(23.0 \%)$ were the most experienced symptoms by Natnael et al. ${ }^{11}$ Blurred vision, eyestrain, and eye irritation were the commonest reported symptoms of CVS with proportion of $62.60 \%$, $47.63 \%$, and $47.40 \%$, respectively by Awrajaw and his colleagues. ${ }^{12}$ The most common complaint reported by $\mathrm{P}$. Ranasinghe et al was headache $(45.7 \%)$, followed by dry eyes $(31.1 \%)$, whereas the least common complaint was changes in visualizing colours $(9.3 \%) .{ }^{13}$

Eye fatigue and discomfort due to constant focusing and refocusing of the eye when a person stares at a computer screen for long hours. Inappropriate sitting position also gives discomfort and stress to the eye, which leads the eye to be more focused and causes the eye muscles more spastic and experience symptoms of CVS. Symptoms were less when the viewing angle is less than $15^{\circ}$ whereas more severe symptoms were observed in improper viewing angle above $15^{\circ}$. Higher viewing angles expose a greater area of conjunctiva and cornea to air and increase the chances of dryness and irritation.

Various studies have revealed that risk factor to the development of CVS was wearing corrective spectacles for refractive errors because the letters on the monitor are in the form of tiny dots called pixels which causes the eyes to accommodate more so as to focus a much clearer image. ${ }^{14-16}$ It is believed that spectacles prescribed by professionals with adequate anti-glare or anti- reflection protective surface might decrease these symptoms of CVS.

Duration of computer usage also significantly predicted the risk of CVS. Evidence from many other studies supports these findings. ${ }^{17,18}$ Rahman and Sanip reported in their study revealed that working on computer for more than $7 \mathrm{hr}$ per day was a significant predictor for CVS. ${ }^{19}$ However, in our study 97 (33\%) individuals used computer around 4-6 hours per day. And 145 participants had agreed to have been using mobile phone for more than 4 hours. The symptoms of headache, eye strain, dryness, burning, grittiness, heaviness or watering, stiff shoulders, low back pain and general fatigue were reported higher with increasing duration of daily computer use.

Those working on computer for more than 20 minutes without break were nearly 2 times more likely to suffer from CVS as compared to those taking break within 20 minutes. ${ }^{19-22}$

In the present study $142(44.4 \%)$ participants took breaks as preventive measure after $1 \mathrm{hr}$ and $87(27.2 \%)$ after 20 minutes. Taking breaks in-between work, looking at far objects in-between work, massaging the eyes and washing the eyes with water were some of the preventive measures employed. Many of the visual symptoms experienced by the participants reduced after stopping computer work. Out of 320 participants only 42 participants $(12.4 \%)$ were aware of CVS.

\section{Conclusion}

Some of the strategies found beneficial in preventing / reducing the symptoms of CVS are keeping the computer screen away which reduces eye strain, computer monitor at a viewing angle of $15^{0}$ lower than horizontal level, taking regular small breaks to relax accommodation, maintaining good sitting posture to avoid neck pain and back pain, correction of visual problems by wearing spectacles or contact lenses and optimum lighting, contrast and 
brightness.

\section{Source of Funding: None.}

\section{Conflict of Interest: None.}

\section{References}

1. Blehm C, Vishnu S, Khattak A, Mitra S. Computer vision syndrome: A review. Surv Ophthalmol. 2005;50:253-62.

2. American Optometric Association. Computer Vision Syndrome (CVS). Available from: http://www.aoa.org/x5374.xml. [Last accessed on 2011 Mar 21].

3. Hayes JR, Sheedy JE, Stelmack JA, Heaney CA. Computer use, symptoms, and quality of life. Optom Vis Sci. 2007;84:739-45.

4. Begley CG, Chalmers RL, Abetz A, Venkataraman K. The relationship between habitual patient-reported symptoms and clinical signs among patients with dry eye of varying severity. Invest Ophthalmol Vis Sci. 2003;44:4753-61.

5. Gowrisankaran S, Sheedy JE, Hayes JR. Eyelid squint response to asthenopia-inducing conditions. Optom Vis Sci. 2007;84:611-19.

6. Himebaugh NL, Begley CG, Bradley A, Wilkin- son JA. Blinking and tear break-up during four visual tasks. Optom Vis Sci. 2009;86:106-14.

7. Sheedy JE, Gowrisankaran S, Hayes JR. Blink rate decreases with eyelid squint. Optom Vis Sci. 2005;82:905-11.

8. Seshadhri Arumugam, Krishna Kumar, Raja Subramani and Satheesh Kumar. Prevalence of Computer Vision Syndrome among Information Technology Professionals Working in Chennai. World J Med Sci. 2014;11(3):312-4.

9. Reddy SC, Low CK, Lim YP, Low LL, Mardina F, Nursaleha MP. Computer vision syndrome: a study of knowledge and practices in university students. Nepal J Ophthalmol. 2013;5(10):161-8

10. Logaraj M, Madhupriya V, Hegde S. Computer vision syndrome and associated factors among medical and engineering students in Chennai. Ann Med Health Sci Res. 2014;4(2):179-85

11. Assefa NL, Zenebe D, Weldemichael, Alemu HW, Anbesse DH. Prevalence and associated factors of computer vision syndrome among bank workers in Gondar City, northwest Ethiopia, 2015. Clin Optom. 2017;9:67-76.

12. Awrajaw Dessie, Fentahun Adane, Ansha Nega, Sintayehu Daba Wami, and Daniel Haile Chercos. Computer Vision Syndrome and Associated Factors among Computer Users in Debre Tabor Town, Northwest Ethiopia. J Environ Public
Health. 2018

13. P. Ranasinghe, W. S. Wathurapatha, Y. S. Perera, D. A. Lamabadusuriya, S. Kulatunga, N. Jayawardana, P. Katulanda. Computer vision syndrome among computer office workers in a developing country: an evaluation of prevalence and risk factors. BMC Res Notes. 2016;9:150.

14. Rahman ZA, Sanip S. Computer user: demographic and computer related factors that predispose user to get computer vision syndrome. Int J Bus, Humanit Technol. 2011;1(2):8491.

15. Reddy SC, Low C, Lim Y, Low L, Mardina F, Nursaleha M. Computer vision syndrome: a study of knowledge and practices in university students. Nepal J Ophthalmol. 2013;5(2):161-8.

16. Logaraj M, Madhupriya V, Hegde S. Computer vision syndrome and associated factors among medical and engineering students in chennai. Ann Med Health Sci Res. 2014;4(2):179-85.

17. Reddy SC, Low C, Lim Y, Low L, Mardina F, Nursaleha M. Computer vision syndrome: a study of knowledge and practices in university students. Nepal J Ophthalmol. 2013;5(2):161-8.

18. Portello JK, Rosen Eld M, Bababekova Y, Estrada JM, Leon A. Computer- related visual symptoms in o ce workers. Ophthalmic Physiol Opt. 2012;32(5):375-82.

19. Rahman ZA, Sanip S. Computer user: demographic and computer related factors that predispose user to get computer vision syndrome. Int J Bus, Humanit Technol. 2011;1(2):8491.

20. Logaraj M, Madhupriya V, Hegde S. Computer vision syndrome and associated factors among medical and engineering students in Chennai. Ann Med Health Sci Res. 2014;4(2):179-85.

21. Agarwal S, Goel D, Sharma A. To evaluate the factors contributing to Ocular complaints in computer users. J Clin Diagn Res. 2013;7(2):331-5.

22. Logaraj M, Priya VM, Seetharaman N, Hedge SK. Practice of Ergonomic Principles and computer vision syndrome (CVS) among under graduates' students in Chennai. Nat J Commun Med. 2013;3(2):111-6.

How to cite this article: Darshan SM, Sangeetha T, Kumar MH. Prevalence of computer vision syndrome among computer users of Kolardistrict. Indian J Clin Exp Ophthalmol 2019;5(3):326-9. 